\title{
"Comparação entre os teores de mercúrio em amostras cruas e cozidas de mexilhão Perna perna (LINNAEUS, 1758)"
}

\section{"Correlation among mercury substances in raw and cooked samples of mussel Perna perna (LINNAEUS, 1758)"}

\author{
Isabela Rocha Novaes, 'Sérgio Carmona de São Clemente," Eliane Teixeira Mársico,"” \\ Nelson Nebel Santos, "e Luiz César Zamborlini"
}

\begin{abstract}
Resumo
Foi determinado mercúrio total, pela técnica de espectrometria de absorção atômica por arraste de vapor frio, em 64 amostras de mexilhão Perna perna (LINNAEUS, 1758), cultivados na Baía de Guanabara, em área próxima à Fortaleza de Santa Cruz, Niterói - Rio de Janeiro. As amostras foram divididas em dois lotes, sendo que o primeiro, composto por mexilhões crus, apresentou média de $0,007 \mathrm{mg} / \mathrm{g}$, enquanto que o segundo, composto por mexilhões cozidos por 20 minutos à temperatura de $100^{\circ} \mathrm{C}$, apresentou média de $0,010 \mathrm{mg} / \mathrm{g}$. A análise estatística de variância indicou que a diferença entre as médias das amostras cruas e cozidas é significativa, comprovando que o processamento utilizado concentra o teor de mercúrio nos tecidos dos mexilhões.
\end{abstract}

Palavras-chave: alimento cozido; alimento cru; mercúrio; mexilhão; Perna perna.

\section{Introdução}

Os mexilhões, como o pescado em geral, são alimento bastante apreciado por grande parte da população, sendo encontrado em restaurantes especializados em "frutos do mar" nas mais variadas apresentações. Servem, ainda, como fonte de alimento para muitas famílias, que têm nos produtos da pesca sua fonte de subsistência.

Pádua (1992), considera que os organismos aquáticos têm uma capacidade "particularmente" maior de concentrar elementos ou substâncias metalo-orgânicas. Isso pode ocorrer durante o processo de alimentação, seja por simples filtração do meio líquido, ou através da cadeia trófica e por contato direto entre o metal com o tegumento de peixes, crustáceos e moluscos. Wood (1974) divide as substâncias tóxicas em materiais tóxicos de ocorrência natural e materiais tóxicos sintetizados industrialmente. Aqueles, cuja periculosidade depende da distribuição no ambiente, em condições normais, permanecem relativamente constantes devido ao processo biológico natural de síntese e degradação, não causando, assim, problemas para a saúde pública. Estes, contudo, quando lançados em grande quantidade no sistema hídrico, não são totalmente degradados, contaminando o ambiente e, conseqüentemente, os seres que nele vivem. Segundo Silva et al. (1983), o mercúrio no sedimento está aparentemente em um estado insolúvel, mas pode entrar na cadeia alimentar através da ação de microorganismos aquáticos. Tollefson e Cordle (1986) afirmam que qualquer forma de mercúrio em ambiente aquático, seja oriundo de fonte natural ou antropogênica, é capaz de ser convertida em metilmercúrio, que será incorporado aos peixes e outros organismos aquáticos.

Os efeitos fisiológicos decorrentes da ingestão de compostos contendo mercúrio foi estudada por Tollefson e Cordle (1986), onde relatam que o metilmercúrio tem uma meia-vida no pescado de aproximadamente 2 anos, o que corresponde a 2 a 5 vezes a meia-vida do mercúrio inorgânico.

De acordo com Diaz et al. (1994), muitos governos têm legislações oscilando entre 0,3 e 1,0 p.p.m. em relação ao grau de tolerância quanto aos níveis de mercúrio total em pescado.

Para o Brasil, a Comissão Nacional de Normas e Padrões para Alimentos (1975) fixou o limite de 0,5 p.p.m. de mercúrio total para peixes, crustáceos e moluscos. D'Amato et al. (1997), em um levantamento sobre os índices de mercúrio presentes em mexilhões Perna perna, oriundos da praia de Piratininga e Baías de Guanabara e Sepetiba, encontraram valores variando entre 0,010 a $0,127 \mathrm{mg} / \mathrm{g}$.

\footnotetext{
* Aluna Graduação Medicina Veterinária - UFF - Bolsista Iniciação Científica.

"* Professor - Depto. de Tecnologia dos Alimentos - Faculdade Veterinária - UFF - Rua Vital Brazil Filho, 64 - Vital Brazil - Niterói - RJ - $24230-340$.

** Mestranda em Higiene Veterinária e Processamento Tecnológico de P.O.A. - UFF.
} 
Estudos correlacionando teores de mercúrio em amostras de pescado cruas e processadas foram realizados com conclusões controversas. Mariño e Martin (1976) mostraram que o mercúrio incorporado aos peixes fixa-se em forma de metilmercúrio aos radicais sulfidrilas das proteínas, o que impossibilita a sua eliminação quando submetido a cozimento ou a outro processamento. Ao contrário do estudo mencionado acima, Garcia et al. (1998) realizaram um trabalho sobre o teor de mercúrio em pescado de origem marinha, abordando diversas fases tecnológicas como: peixe assado, à milanesa, à vinagrete e frito ao molho de tomate, concluindo que os processamentos em maior ou menor grau contribuíram para a diminuição do teor de mercúrio.

Em concordância parcial com Mariño e Martin (1976), Souza e Goyanes (1992), concluíram em seus trabalhos que as mercaptanas ligadas ao mercúrio somente se hidrolisam com ácidos fortes, exibindo uma grande estabilidade térmica. Por este motivo, processamentos tecnológicos, como apertização, salga, tratamento com ácidos fracos e defumação não modificam em termos absolutos o teor de mercúrio total do produto, provocando, no entanto, a desidratação do mesmo com o conseqüente aumento do teor do mercúrio por unidade de peso.

Em face do exposto, este trabalho objetiva avaliar o teor de mercúrio em mexilhões e possíveis alterações decorrentes após processamento por cocção.

\section{Material e métodos}

Foram analisadas 64 amostras de mexilhão Perna perna (LINNAEUS, 1758), cultivados em área próxima à Fortaleza de Santa Cruz, Niterói - RJ, coletados no ano de 1997. As amostras foram acondicionadas em sacos plásticos e transportadas, em recipiente isotérmico (caixa de isopor) contendo gelo, ao laboratório de Controle Físico Químico de Produtos de Origem Animal, da Faculdade de Veterinária da Universidade Federal Fluminense.

As amostras foram congeladas em freezer comercial comum a $-17^{\circ} \mathrm{C}$, metade em seu estado cru, com concha, e a outra metade após o processo de cozimento por 20 minutos, desconchada. Em seguida, foram retiradas do freezer e colocadas sob refrigeração a $5^{\circ} \mathrm{C}$ para descongelamento, horas antes da dosagem de mercúrio.

Todo material de vidro utilizado durante as análises foi lavado e rinsado com água destilada e, após sucessivas análises, deixado de molho em solução de ácido nítrico a $2 \%$ por 24 horas.

Para o processo de mineralização das amostras, seguiuse a técnica de Deitz, Sell e Bristol (1973), com algumas modificações.

Com auxílio de uma faca inox, os mexilhões crus foram desconchados e, tanto as amostras cruas quanto as cozidas foram cominuídas em placa de Petri.
Para cada determinação, foram colocados nos tubos de hidrólise $0,040 \mathrm{~g}$ de pentóxido de vanádio, utilizado como catalisador e a amostra de mexilhões individuais previamente cominuída e pesada individualmente.

Posteriormente, foram adicionados $15 \mathrm{ml}$ de ácido nítrico concentrado. Os tubos foram agitados e colocados em bloco digestor a $140^{\circ} \mathrm{C}$ por 25 minutos. No decorrer desse tempo, procedeu-se à agitação dos tubos várias vezes para intensificar a liberação de vapores avermelhados de óxido de nitrogênio. Após resfriamento ao ar por 10 minutos adicionaram-se lentamente $30 \mathrm{ml}$ de ácido sulfúrico concentrado, aqueceu-se a $140^{\circ} \mathrm{C}$ por 25 minutos, com agitação em intervalos regulares. Após resfriamento ao ar por 5 minutos, adicionaram-se $10 \mathrm{ml}$ de água seguindo-se aquecimento por mais 15 minutos. Após o resfriamento, o volume foi completado com água destilada até $100 \mathrm{ml}$ e resfriados em banho de gelo por 30 minutos.

O mercúrio foi reduzido a mercúrio metálico pela adição de $10 \mathrm{ml}$ de solução de cloreto estanoso a $10 \% \mathrm{em} \mathrm{HCl}$.

Para a determinação do mercúrio total, utilizou-se o analisador Bacharach Coleman modelo MAS-50B, que utiliza a técnica de absorção atômica por arraste de vapor a frio, fornecendo os resultados em microgramas de mercúrio.

\section{Resultados}

As análises das 64 amostras mostraram que os valores de mercúrio variaram de 0,001 a $0,014 \mathrm{mg} / \mathrm{g}$ nas 32 amostras de mexilhões crus e de 0,002 a $0,017 \mathrm{mg} / \mathrm{g}$ nas 32 cozidas. Portanto, dentro dos padrões fixados pela Comissão Nacional de Normas e Padrões para Alimentos.

As médias dos resultados obtidos na determinação do mercúrio total nas amostras dos mexilhões crus e cozidos podem ser observados na Tabela 1.

Tabela 1: Média da concentração de mercúrio em mg/g em amostras cruas e cozidas de mexilhões $P$. perna.

\begin{tabular}{c|c|c|c|c}
\hline MEXILHÓES & NoAMOSTRAS & $\begin{array}{c}\text { VALOR MÁX. } \\
(\mu \mathrm{g} / \mathrm{g})\end{array}$ & $\begin{array}{c}\text { VALOR MÍN. } \\
(\mu \mathrm{g} / \mathrm{g})\end{array}$ & $\begin{array}{c}\text { MÉDIA } \\
(\mu \mathrm{g} / \mathrm{g})\end{array}$ \\
\hline CRUS & 32 & 0,014 & 0,001 & 0,007 \\
\hline COZIDOS & 32 & 0,017 & 0,002 & 0,010 \\
\hline
\end{tabular}

Nos resultados de determinação quantitativa de mercúrio, foram utilizados Análise de Variância e Teste $F$, onde $\mathrm{a}=95$, disponíveis no programa SAS (Statistical Analysis System), versão 6.08, de 1985, para microcomputador.

Os testes estatísticos mostraram que os valores das amostras cruas e cozidas são significativamente diferentes entre si $(p<0,0004)$. 
Na Tabela, 2 observa-se a análise de variância para as médias dos resultados entre as amostras cruas e cozidas.

Tabela 2: Análise de variância das médias dos resultados da determinação de mercúrio.

\begin{tabular}{c|c|c|c|c}
\hline $\begin{array}{c}\text { FONTE DE } \\
\text { VARIAÇÃo }\end{array}$ & g.I. & $\begin{array}{c}\text { S.Q. } \\
(\mu \mathrm{G} / \mathrm{G})\end{array}$ & $\begin{array}{c}\text { Q.M. } \\
(\mu \mathrm{G} / \mathrm{G})\end{array}$ & $\begin{array}{c}\text { VALOR DE F } \\
(\mu \mathrm{G} / \mathrm{G})\end{array}$ \\
\hline MODELO & 1 & 0,0002 & 0,00018 & 14,32 \\
\hline ERRO & 62 & 0,0008 & 0,00001 & \\
\hline TOTAL & 63 & 0,0010 & & \\
\hline (P<0,0004) & \multicolumn{4}{|c}{}
\end{tabular}

$R^{2}$ (coeficiente de determinação do modelo) $=0,20$

C.V. (coeficiente de variação) $=42,76 \%$

\section{Discussão}

O valor médio encontrado em amostras cruas (' $X=0,007)$ é bem inferior aos observados por Mariño e Martin (1976) e Sousa e Goyanes (1992), na Espanha, que foram de 0,03 $\mathrm{mg} / \mathrm{g}$ e $0,07 \mathrm{mg} / \mathrm{g}$, respectivamente.

Comparando-se estes resultados com a média mais baixa encontrada por D'Amato et al. (1997) (' $X=0,0297)$, pode-se observar que o teor de mercúrio dos mexilhões utilizados neste trabalho é bem inferior, o que confirma a afirmativa de muitos autores de que o local de coleta influencia bastante nos índices do contaminante. Os resultados encontrados são justificados pelo fato de o local de cultivo dos mexilhões utilizados no presente trabalho apresentar menor poluição que os outros pontos da Baía de Guanabara, onde foram feitas as coletas pelo referido autor.

Correlacionando os valores das amostras cruas e cozidas analisadas, pode-se observar que houve um aumento relativo do teor de mercúrio em decorrência da cocção, fato possivelmente associado à desidratação da amostra durante o processamento.
Comparando os resultados de $\mathrm{Hg}$ relativos à cocção, verifica-se serem compatíveis aos encontrados por Sousa e Goyanes (1992), que mostraram através de trabalho realizado com peixes e moluscos que a concentração de mercúrio cresce proporcionalmente com o tempo de cocção, evidenciando a progressiva desidratação do produto. Resultado também encontrado por Mariño e Martin (1976), que também demonstraram que o mercúrio que se encontra no pescado não é eliminado por cocção ou outro tratamento tecnológico, por estar fixado em forma de metilmercúrio aos grupos sulfidrilas das proteínas.

Por outro lado, Garcia et al. (1988), demonstraram que pescados cozidos e assados têm o índice de mercúrio sensivelmente diminuído e que o calor é uma fonte de perda de mercúrio. Possivelmente, a diferença de resultados pode estar relacionada à temperatura dos processamentos utilizados por estes autores, que foi mais elevada, fazendo com que houvesse volatização do metal, o que aparentemente não ocorre quando a temperatura máxima utilizada é de $100^{\circ} \mathrm{C}$.

Embora não se tenha encontrado níveis elevados de mercúrio total, deve-se lembrar que a principal forma do metal encontrada em pescado é o metilmercúrio, que além de ser altamente tóxica, possui efeito cumulativo, indicando que a ingestão rotineira de mexilhão contaminado é um fator de risco para a saúde pública.

\section{Conclusões}

- Apesar dos valores de mercúrio encontrados estarem abaixo do valor máximo permitido, os riscos não devem ser descartados devido ao fato de o mercúrio apresentar efeito cumulativo;

- Demonstra-se que o processamento pela cocção concentrou o teor de mercúrio encontrado nos mexilhões;

- É imprescindível um monitoramento da poluição por mercúrio na Baía de Guanabara.

\section{Abstract}

Determinations of total mercury by spectrometric atomic absorption technique on cold vapor were carried out in sixty-four samples of mussels Perna perna (LINNAEUS, 1758), grown up in Guanabara Bay, near Santa Cruz Fort, Niterói - Rio de Janeiro. The samples were divided into two groups. The mean value of the first group was $0,007 \mathrm{mg} / \mathrm{g}$ while the other one, which was cooked in a temperature of $100^{\circ} \mathrm{C}$ for twenty minutes. had a mean value of $0,010 \mathrm{mg} / \mathrm{g}$. The variance analysis indicated that the difference between both samples' groups was significant, proving that cooking process concentrates mercury in mussels' tissues.

Keywords: cooked food; raw food; mercury; mussels; Perna perna; raw. 


\section{Referências bibliográficas}

BRASIL. Comissão de Normas e Padrões para Alimentos. Resolução no 18/75. Fixa limites de tolerância para o Mercúrio em alimentos. Diário Oficial da União, Brasília, DF, 9 dez.1975.

D'AMATO, C. Levantamento sobre os índices de Mercúrio presentes em mexilhões Perna perna (LINNAEUS, 1758) oriundos de Piratininga e Baía de Guanabara e Sepetiba. Higiene Alimentar, v. 11, n. 50, p. 30-35, 1997.

DEITZ, F. D., SELL, J. L., BRISTOL, D. Metals and other elements - rapid, sensitive method for determination of Mercury in a variety of biological samples. J. Assoc. Off. Anal. Chem., v. 56, no. 2, p. 378-382, 1973.

DIAZ, C. et al. Concentrations of Mercury in fresh and salted marine fish from the Canary Islands. J. Food Prot., v. 57, no. 3, p. 246-248, 1994.

GARCIA, M. T. H., PARA, M. C. M., MASOUD, T. A. Variacion en la cantidad de mercurio en muestras de pescado sometidas a diversos procesos culinarios. An. de Bromatol., Madrid, v. 40, n. 2, p. 291-297, 1988.
MARIÑO, M., MARTIN, M. Contenido de Mercurio en distintas especies de moluscos y pescados. An. de Bromatol., Madrid, v. 28, n. 2, p. 155-178, 1976.

PÁDUA, H.B. Aspéctos do comportamento dos metais pesados em organismos aquáticos. Abrapoa, n. 23, p. 20-21, 1992.

SILVA, C. C. do AMARAL e, TOMMASI, L. R., BOLDRONI, C. V., PEREIRA, D. N. Níveis de Mercúrio na Baixada Santista. Ciênc. e Cult., São Paulo, v. 35, n. 6, p. 771-773, 1983.

SOUSA, J. V. B. de, GOYANES, A. L. Contenido de Mercurio en produtos de la pesca por espectrofotometría de absorción atómica en vapor frio. An. Bromatol., Madrid, v. 44, n. 1, p. 45-57, 1992.

TOLLEFSON, L., CORDLE, F. Methylmercury in fish : a review of residue levels, fish consuption and regulatory action in the United States. Environ. Health Perspect., n. 68, p. 203-208, 1986.

WOOD, J. M. Biological cycles for toxic elements in the environment. Science, v. 183, no. 4129, p. 1049-1052, 5 Mars. 1974. 